\title{
Developing Noise Maps to Monitor Railway Train Noise at Four Different Keretapi Tanah Melayu (KTM) Stations
}

\author{
F. E. Selamat ${ }^{*}$ and F. L. Abdul Rahim \\ Department of Mechanical Engineering, Universiti Tenaga Nasional, \\ 43000 Kajang, Selangor, Malaysia \\ *Email: Farah.Elida@uniten.edu.my \\ Phone: +60389216300; Fax: +60389212119
}

\begin{abstract}
Due to the rapid increase in the growth of public transportation especially railway train, the responsibility to maintain the noise level within the acceptable range at the stations is crucial. Policies on noise control have been developed in most part of the world. Passengers ride the train daily and they are continuously being exposed to high level of noise. A powerful tool with the ability to measure ambient noise level and represent it on a map shall help acoustical engineers and safety officers to identify noise sources, and how it spreads, thus, enabling them to make decisions relating to noise control and management. Maps were drawn to show spatial distributions of noise and source classification. This project focuses on the noise issue at various KTM stations by collecting noise level data using a sound level meter (SLM) and producing noise maps by means of Sketchup Pro software to represent the noise band. The noise level gradually reduces as we go further away from the source. The Leq of the four stations are between 60-70 dB, which are assessed as acceptable. The noise level data are then used to develop noise maps for the four KTM stations.
\end{abstract}

Keywords: Noise; railway train; noise map; sound level meter; acoustic.

\section{NOMENCLATURE}

$\begin{array}{ll}\text { Ave } & \text { average } \\ \text { dB } & \text { decibel } \\ \text { dB(A) } & \text { decibel A weighted } \\ \text { GRAS } & \text { Gunnar Ramussen acoustic system } \\ \text { KTM } & \text { Keretapi Tanah Melayu } \\ \text { KTMB } & \text { Keretapi Tanah Melayu Berhad } \\ \text { L }_{\text {Aeq }} & \text { equivalent continuous noise level (A weighted) } \\ \mathrm{L}_{\text {eq }} & \text { equivalent continuous noise level } \\ \mathrm{L}_{\max } & \text { maximum level of noise } \\ \mathrm{L}_{\min } & \text { minimum level of noise } \\ \mathrm{L}_{\mathrm{p}} & \text { sound pressure level } \\ \mathrm{SLM} & \text { sound level meter }\end{array}$




\section{INTRODUCTION}

Acoustic engineers have designed ways to reduce unwanted noise, which is known as noise control, and deemed more important now than ever. The practice of acoustics exists in almost all aspects of modern society with the plainest evidence being the audio and noise control industries. One of the main goals of acoustic engineering is to reduce the undesired high volume of noise. Unwanted noise can have huge impacts on human and animal health and well-being, loss of concentration, and cause hearing loss [1].

Noise is an excessive sound that might harm human or animal life and disrupt their activity. Noise pollution may harm both humans' behavior and health, and it is among the most universal pollutants today. Noise from trains, road traffic, jet planes, and even machines are among the unwanted sounds produced and are routinely transmitted into the air. Noise pollution can cause high amount of stress levels, loss in hearing, high blood pressure, and sleep disturbance.

Most of the researches emphasize on the impact of noise on the human hearing auditory system and it is now well known that exposure to high level of sound can lead to hearing loss and hearing impairment [2]. Noise could lead to human annoyance which may result in quality reduction and affect the health and physiological wellbeing. Annoyance has been used as a term for every negative feeling or emotion similar with displeasure, disturbance, dissatisfaction, irritation, and nuisance [3].

Exposure to high levels of noise has produced a lot of negative effects in both short and long-term. Long term effects include damage to human health and there is a possibility that repeated exposure to elevated noise levels, for example at train stations, may affect the residents living nearby or transit riders' hearing and circulatory systems. Research has shown that daily commuters who always use stations with noisy environment over the course of many years may suffer from hearing loss [4]. Risks, such as ischemic heart disease, have been found in those who are exposed to high noise levels [5]. While research has not clearly shown health problems within the passengers, the possibility of passengers who commute by trains to experience long-term health problems is high.

Noise produced by railway trains is one of the major sources of dissatisfaction in residential areas. Train noise is one of the vehicle noises created by the moving trains where noises can be heard inside and outside the train. Various parts of the train along with the wheels can produce noise. Train noise depends on the type of rails, train speed, and regime of movement (breaking or non-breaking). The level of noise also depends on the spinning of wheels, as well as moving throughout connections between rails [6]. Since many sectors of the society are affected by the increase of noise level in recent years, noise and urban planning have been studied extensively based on noise mapping [7]. By using noise mapping, the changes in the noise environment could be predicted.

The study of noise in big cities represents a huge challenge due to the high population density and the combination of different noise sources contributing to the overall acoustical environment. The study method must be carefully chosen to precisely describe it [8]. Due to high cost, complexity, and mainly laborious task of measuring the acoustic situation of an area and its surrounding, simulations might be used using a prediction software that can calculate noise levels in a quicker way. The prediction results can be compared with the real measures, which can be used to calibrate the model [8].

The noise problem of railway trains has attracted more and more attentions due to the requirements for improving the passengers' comfort and the living environment 
standard. The noise radiated by the railway system has significantly influenced both passengers inside the trains and the residents along the railway lines [9]. Many researches on railway noise have been conducted since the early 1970s and huge progresses have been made during the past years. It has been widely accepted that during conventional travelling speeds, the generation of railway noise is mainly because of the wheel and rail frictions [9].

Currently, the development of monitoring and simulator software related to the propagation of noises or transportation, and associated with the complexity of sources, receivers or predictive models, has become a main issue for improving public health and quality of life [10]. Noise prediction models play an important role in evaluating the contemporary changes in traffic, railway, airport, and factory or design schemes of town planning. Environmental noise has become a part of the environmental impact studies and direction for urban development for various countries [10].

In European countries, they introduced noise maps in the early 2002 for cities with more than 250,000 inhabitants. Normally, assessments of railway train noise rely on simple numerical expressions [11]. Hence, the effect of the noise on areas outside of the measurement space could not be determined and most people cannot figure out the implications of these numerical expressions. Nevertheless, a noise map can present the results by using pictures instead of numbers, a method that can be easily understood [11].

Therefore, to overcome the disadvantages of the previous methods, a low-cost method that is capable to measure the noise level of the train stations has been produced. The next process involved in this project is to use the data obtained from the sound measuring device and map them onto the contour. This is to ensure that the user will be able to translate the information easily. A further benefit of having a noise model is that it can be used in noise action planning, to assess the effects of transportation and other development projects. Therefore, the aftermath of new roads or railway stations can be assessed, and suitable noise mitigation can be designed to minimize its impact.

Hence, the objectives of this study are to collect data of the noise level in order to measure the environmental noise caused by railway trains and to design noise map using computational noise mapping at four different Keretapi Tanah Melayu (KTM) stations.

\section{Allowable Train Noise Level in Malaysia}

In most developed countries, benchmark for air pollution and noise exposure is a crucial part of the environmental policy in order to improve the local environmental quality. Often these standards are based on professional judgments and do not consider peoples' preferences.

In Malaysia, the Department of Environment (DOE) had enforced the Environmental Quality Act 1947 to prevent, abate and control pollution, which includes restrictions on noise pollution. The Planning Guidelines for Environmental Noise Limits and Control publications by DOE provide guidance on acceptable noise limits for various types of land use and human activities. The recommended limiting sound levels $\left(\mathrm{L}_{\text {Aeq }}\right)$ from railways including transit trains is shown in Table 1 [12]. 
Table 1. Limiting sound level $\left(\mathrm{L}_{\text {Aeq }}\right)$ for railways including transits.

\begin{tabular}{lccc}
\hline \multicolumn{1}{c}{ Land use category } & $\begin{array}{c}\text { Daytime } \\
\text { am }-10 \mathrm{pm} \\
(\mathrm{dBA})\end{array}$ & $\begin{array}{c}\text { Nighttime } \\
10 \mathrm{pm}-7 \text { am } \\
(\mathrm{dBA})\end{array}$ & $\begin{array}{c}\mathrm{L}_{\text {max }} \\
\text { (day and night) }\end{array}$ \\
\hline $\begin{array}{l}\text { Noise sensitive areas, areas } \\
\text { of deployment, low density }\end{array}$ & 60 & 50 & 75 \\
$\begin{array}{l}\text { Suburban and urban } \\
\text { settlement }\end{array}$ & 65 & 60 & 80 \\
$\begin{array}{l}\text { Commercial, business } \\
\text { Industry }\end{array}$ & 70 & 65 & 80 \\
\hline
\end{tabular}

\section{EXPERIMENTAL SET UP}

\section{Research Setting}

The noise levels over an area varies with time. Noise levels increase as a train approaches, and reduce again after it has passed, which would cause short-term variations in noise level. In the slightly longer term, noise levels may be higher in peak periods and lower in off-peak periods. This means that the long term average noise level is where the noise sources are well-defined, such as roads, or railway stations, as done in this study.

Keretapi Tanah Melayu Berhad (KTMB) train stations are selected for this assessment. KTM is widely known and it is the main rail operator in Peninsular Malaysia. It was built during the colonial era by the British and it was first built to transport tin due to lack of proper roads. KTM Komuter train is another major milestone in Malaysia's rail industry, first introduced in 1995. It is an electrified commuter rail service brand operated by the KTM, and caters especially to commuters in Kuala Lumpur and the surrounding suburban areas. KTMB provides 248 commuter services daily and serves 45 stations along 175 route-kilometers. The Komuter railway consists of two main sections, which are the Seremban Line and Port Klang Line, operating at 15 minutes' interval time during peak hours and 20 minutes' interval time during off-peak hours. The Rembau and Tanjung Malim shuttle service running at the Seremban and Ipoh line, respectively, operate at thirty minutes' frequency [13]. It is a heavily utilized mode of transportation by commuters working in Kuala Lumpur as the service is an alternative for road travel, which is occasionally hampered by congestion.

Four locations of KTM stations have been selected in Selangor. These locations have been identified and divided into two categories, where two are indoor stations and another two are outdoor stations. The two indoor stations are KTM KL Sentral station and KTM Kuala Lumpur station, while the two outdoor stations are KTM Serdang station and KTM Bandar Tasek Selatan station.

\section{Measurement Tool}

The device to measure the noise level is Svan 945A Type 1 Sound Level Meter (SLM) and analyzer. It was intended for general acoustic measurements, environmental noise monitoring, occupational health, and safety monitoring. The sound level meter is mounted on a tripod for better reading. There are two types of calibration necessary for 
noise monitoring before proceeding to the next step, which are equipment laboratory calibration and field calibration.

For equipment calibration, it is essential to ensure that the SLM and calibrator have been calibrated in a certified calibration laboratory. The calibrators are required to be calibrated every year and the SLM must be calibrated as per the manufacturer's specifications. A sticker on the SLM and calibrator indicates the last recorded date of laboratory calibration. The SLM that was borrowed from the Universiti Tenaga Nasional has been calibrated by the staff.

Next step is field calibration. The $\mathrm{L}_{\mathrm{p}}$ shown on the meter should match the stated $\mathrm{L}_{\mathrm{p}}$ for the calibrator being used. Standard calibration is generally $94 \mathrm{~dB}(\mathrm{~A})$ but can vary slightly due to the microphone sensitivity e.g. $93.8 \mathrm{~dB}(\mathrm{~A})$. The calibration level should be confirmed with the SLM manufacturer's specifications. The variation before and after the calibrations should be no more or less than $1 \mathrm{~dB}(\mathrm{~A})$. If the deviation of the calibration is greater than $1 \mathrm{~dB}(\mathrm{~A})$, then the results obtained during the assessment are invalid.

The noise measurements were conducted from 17 to 31 October 2016 from 8 am to $6 \mathrm{pm}$. The sound level measurements were taken directly from one station to the next station during the time between 08:00-9:00, 12:00-13:00, and 16:00-17:00 for a period of one hour each. A calibrated Svan 945 Type A SLM and GRAS 40AN 50 mV/Pa 1/2" Condenser Microphone were used for data collection. These devices collected the noise level of the surrounding data, which then will be mapped using the SketchUp Pro.

The measurement worked by analyzing statistical calculations analysis and general acoustic measurements. The measurement recorded noise level then reflected back to the receiver of the sensor. This means that the sensor can only collect one data if it is in a nearby position and this makes it impossible to map the contour with a single data. Therefore, the sensor needs to be near the train station for a 1 hour period. Then the data will take the average noise level along with the maximum and minimum levels of the noise. The SLM was mounted on a tripod at a level of $1.5 \mathrm{~m}$ above the ground for better reading. If the SLM was placed too close to a reflective surface, the noise level will be higher than the actual noise level. To avoid the reflection, the reading needs to be taken more than $3.5 \mathrm{~m}$ away from the reflective surface.

\section{Design Tool}

The software that is used to develop noise mapping in this project is SketchUp Pro 2017. There are other software that can be used to develop noise mapping such as ArcGis and Predictor-LimA, but the SketchUp Pro is used due to its usefulness from the earliest stages of design to the end of construction. SketchUp Pro is one of the most intuitive and easy-to-learn 3D drawing tools existed. It gives the freedom of making changes easily and as quickly as possible, and it is also a tool for creating a complete project.

Modelling sound propagation outdoors is straight forward and easy to use with this software. It also has numerous online instructors and help screens that can help first time users. This software enables users to define the geometry of buildings and the position of noise sources.

This software also requires Google Earth and Noise 3D Online as toolsets for noise calculation and mapping. Google Earth helps users to choose terrain to be put into SketchUp Pro software, while noise 3D online enables users to create 3D and sophisticated acoustic models placed on the Google Earth terrain. The noise 3D Online 
also provides noise calculation results and exports the acoustic model and noise map to Google Earth. This setup provides a perfect planning for the floor plan for acoustic modelling. Defining the geometry of buildings and obstacles and the position of the noise source and emission points in a 3D model is also necessary.

Installation of the noise data using friendly input masks provided by the SketchUp Pro software enables auto configure. The DIN ISO 9613-2 calculation, which is a method for calculating the attenuation of sound during propagation outdoors, provides results within seconds or minutes on the servers.

\section{RESULTS AND DISCUSSION}

\section{Noise Level Data Collection}

Once the noise values from the sound level meter are obtained, the values will then be tabulated daily into 7 different tables. In each table, there will be 3 variables that need to be recorded, which are average noise, equivalent continuous noise level $\left(\mathrm{L}_{\mathrm{eq}}\right)$, and maximum level $\left(\mathrm{L}_{\max }\right)$. As can be seen, Table 2 shows the daily measurement data for a week for Monday until Sunday at the specified KTM stations.

There are several important discussion points from the data collection. First of all, the results of the measurements show that, from the total of 84 measurements, the weighted noise level is concentrated around $68 \mathrm{~dB}(\mathrm{~A})$, which is the level of a continuous noise. Corresponding average noise levels for the KTM are within the range of $70-75 \mathrm{~dB}(\mathrm{~A})$, which represent a good compromise between low noise levels, good privacy, and speech comprehensibility, but there are tonal and higher frequency components in the noise spectrum.

Furthermore, there are interior noise level fluctuations during the transportation that are not desired. Leq is the A-weighted energy mean of the noise level averaged over the measurement period. The continuous steady noise levels $\mathrm{L}_{\mathrm{eq}}$ are dissipating between $65.5 \mathrm{~dB}(\mathrm{~A})$ and $70.0 \mathrm{~dB}(\mathrm{~A})$. $\mathrm{L}_{\max }$ for the 4 stations is within the range of $90-100 \mathrm{~dB}(\mathrm{~A})$ due to loud noise during train arrival.

Based on Table 2, the highest noise level for the 4 stations occur at 8 am -9 am and $4 \mathrm{pm}-5 \mathrm{pm}$. The noise level is the highest during the peak periods, when there is a greater volume of activity, and lowest during off-peak periods especially in the afternoon or at night. 


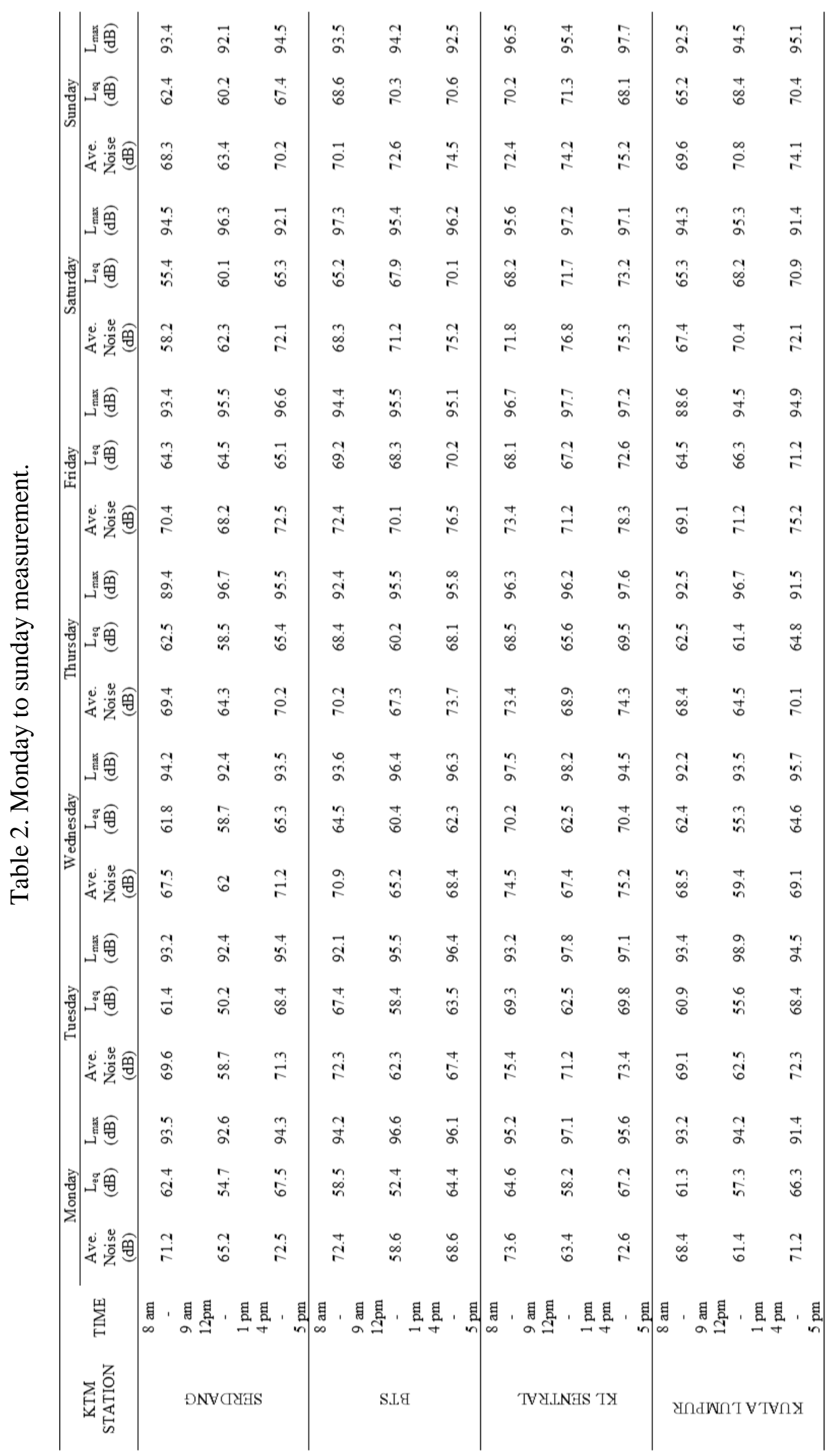




\section{Noise Mapping}

The noise map for each selected station is presented with noise level colour code. The colours shown in the noise maps designed for the 4 KTM stations are based on the noise band $(\mathrm{dB})$ in the colour code. The colour code in Figure 1 is used as reference for the coloured noise maps. As the noise level indicator increases, starting from $55 \mathrm{~dB}$ to 80 $\mathrm{dB}$, the colour will get darker. Meanwhile, for noise level indicator of $55 \mathrm{~dB}$ and below, the colour indicator gets brighter and greener, showing that it is safe for the environment. If the noise level above $55 \mathrm{~dB}(\mathrm{~A})$ lasts for an extended period, the efficiency and well-being of a person will be reduced.

The noise map for KTM Serdang station in Figure 2 shows that the noise from the point source is around $80 \mathrm{~dB}$ and above. The dark red color contour from the surrounding of the map shows that the noise is able to propagate further from the station, which will bring discomfort towards the passersby. The building of the station is able to block low volume level of noise, but it is still unable to decrease the high pitch sound from the train. The noise level for the residential areas near the KTM Serdang station is around $60 \mathrm{~dB}$, which is considered as a normal noise level.

\begin{tabular}{|c|c|c|c|c|}
\hline $\begin{array}{l}\text { Noise band } \\
\text { [dB] }\end{array}$ & Colour & RGB code & HEX code & Name \\
\hline less than 35 & none & - & - & - \\
\hline $35-39$ & & \begin{tabular}{|l|} 
R: 35 \\
G: 132 \\
B: 67 \\
\end{tabular} & $\# 238443$ & Moderate sea green \\
\hline $40-44$ & & \begin{tabular}{|l|} 
R: 120 \\
G: 198 \\
B: 121 \\
\end{tabular} & $\# 78 C 679$ & Greyish green \\
\hline $45-49$ & & $\begin{array}{l}\text { R: } 194 \\
\text { G: } 230 \\
\text { B: } 153\end{array}$ & \#C2E699 & Light greyish chartreuse green \\
\hline $50-54$ & & $\begin{array}{l}R: 255 \\
\text { G: } 255 \\
\text { B: } 178\end{array}$ & \#FFFFB2 & Pale yellow \\
\hline $55-59$ & & $\begin{array}{l}\text { R: } 254 \\
\text { G: } 204 \\
\text { B: } 92\end{array}$ & \#FECC5C & Light brilliant amber \\
\hline $60-64$ & & $\begin{array}{l}\text { R: } 252 \\
\text { G: } 141 \\
\text { B: } 60 \\
\end{array}$ & \#FD8D3C & Brilliant tangelo \\
\hline $65-69$ & & \begin{tabular}{|l|} 
R: 255 \\
G: 9 \\
B: 9 \\
\end{tabular} & \#FF0909 & Light brilliant red \\
\hline $70-74$ & & $\begin{array}{l}\text { R: } 179 \\
\text { G: } 6 \\
\text { B: } 34\end{array}$ & \#B30622 & Moderate amaranth \\
\hline 75-79 & & $\begin{array}{l}\text { R: } 103 \\
\text { G: } 3 \\
\text { B: } 59 \\
\end{array}$ & \#67033B & Dark rose \\
\hline 80 and more & & $\begin{array}{l}\text { R: } 28 \\
\text { G: } 0 \\
\text { B: } 84\end{array}$ & $\# 1 \mathrm{C} 0054$ & Deep blue violet \\
\hline
\end{tabular}

Figure 1. Noise level colour code. 


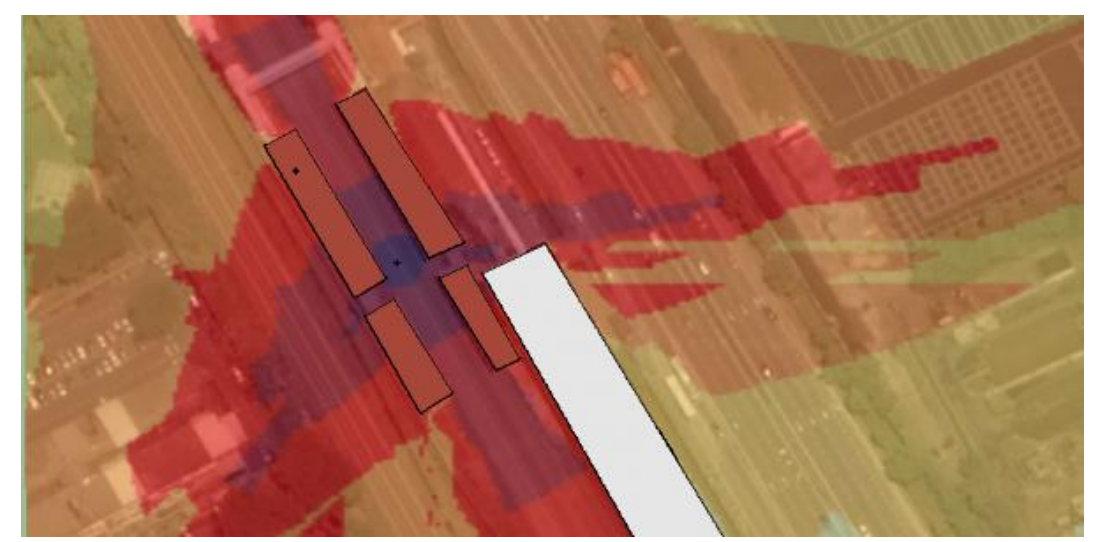

Figure 2. Noise mapping for Serdang station.

The noise map for KTM Bandar Tasek Selatan station in Figure 3 shows that the noise levels from the point source are from $80 \mathrm{~dB}$ and above. The dark red colour contour spread to the northwest area due to the obstacles from the buildings on the south area. The noise will only be able to propagate when there is no obstacle. From the point source, large areas of the map on the north side are on the red colour contour, which show that the areas are affected. There are no residential areas nearby and the noise level is average at around 65-69 dB, which is still considered as safe.

The noise map for KTM KL Sentral station in Figure 4 shows that the noise levels from the point source are from $80 \mathrm{~dB}$ and above. There are two source points due to noise from inside of the building. The dark red color contours are on two sides and spread through areas where there are no buildings that are able to block the noise. There are no residential areas nearby and the noise is still considered as safe. The noise inside the station's building is unable to be mapped due to software limitation.

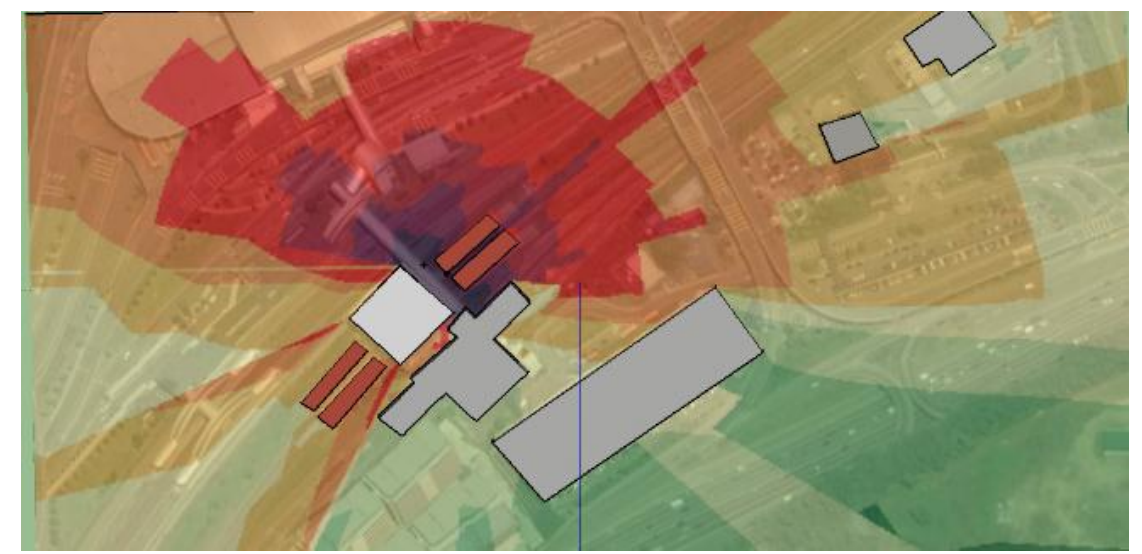

Figure 3. Noise mapping for Bandar Tasek Selatan station. 


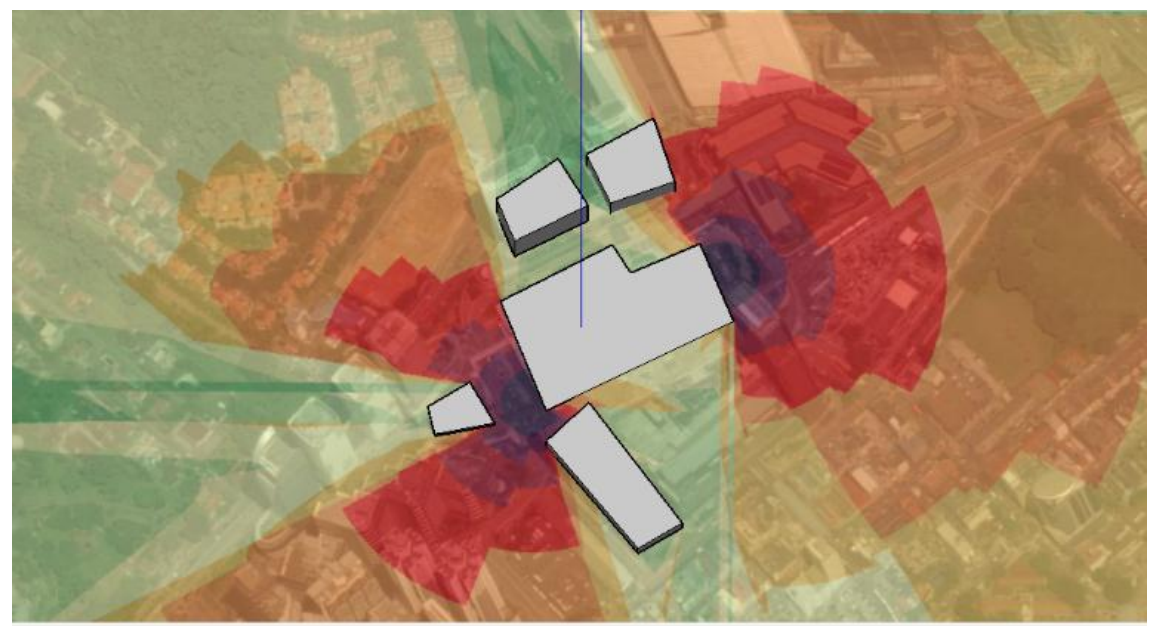

Figure 4. Noise mapping for KL Sentral station.

The noise map for KTM Kuala Lumpur station in Figure 5 shows that the noise levels from the point source are from $80 \mathrm{~dB}$ and above. KTM Kuala Lumpur station is an indoor station but there is an open area where noise can propagate. The red colour contour from the surrounding of the map shows that the noise is able to propagate further away from the station, which will bring discomfort towards the passersby. There are four layers of colour on the noise map. The noise propagates from $80 \mathrm{~dB}$ to $55 \mathrm{~dB}$ (from dark red colour to red amber). There are no residential areas nearby and the noise is average at around 65-69 dB, which is still considered as safe.

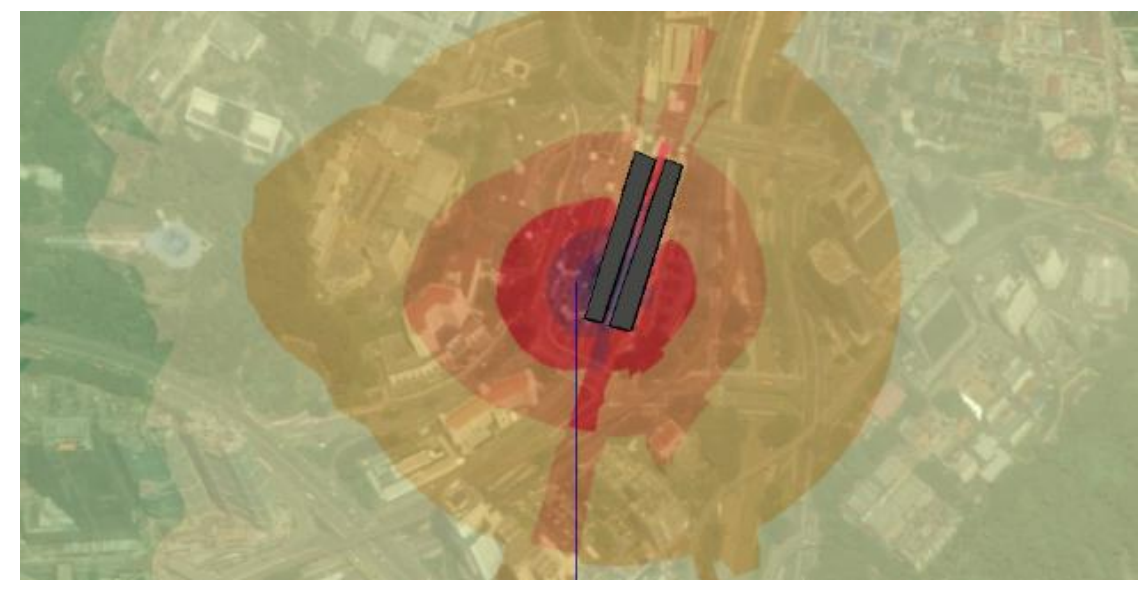

Figure 5. Noise mapping for Kuala Lumpur Station

\section{CONCLUSION}

This study has successfully met the objectives which are to monitor and develop noise maps to monitor railway train noises at four different KTM stations. The existing traditional noise mapping method provides only noise information of one particular height. This does not yield enough information for the noise assessment process. Due to this reason, the $3 \mathrm{D}$ noise models are very useful in order to get complete information on 
noise that may pose health risk to passersby and residents who live near the train stations.

These noise maps shall help and ease the acoustical engineers and safety officers in terms of mapping noise levels as the color code will indicate the areas that are badly affected. The software will produce the noise map by using the data that have been collected and provide future references for the engineers.

The noise level from the point sources that are deep blue violet in color shows noise band of $80 \mathrm{~dB}$ and above. The noise level will gradually reduce as we go further away from the source. Hence, the noise level in the residential area near Serdang KTM station is around $60 \mathrm{~dB}$, which is considered as a normal noise level and the area is therefore, unaffected from the high noise from the station. For the other three stations, there are no residential areas nearby as well. Furthermore, the average noise level for all four stations is between 60 to $70 \mathrm{~dB}$, which is regarded as acceptable.

The noise level between indoor and outdoor stations does not show much difference. The software, SketchUp Pro, is unable to map the noise levels inside the building for KTM KL Sentral station due to software limitation. One of the most important aspects that need to be considered during noise mapping, besides the difference of indoor and outdoor noise levels is the volume of people at the stations. During peak periods, there is a greater volume of activity, which might affect the level of noise during data collection.

Apart from that, the current study also found that there is no significant association between weather and the levels of the noise reading. The sound of the rain does not affect the reading as the sound level meter records the noise level on the normal level of reading the same as during a bright day. This is because the sound level meter can only detect noise which has a high pitch and when it is raining, it does not produce a high pitch, unless there is lightning, however, lightning sound is not included in the current study.

The project that has been done has significant values that can be contributed to the society. Noise mapping has been proved to be important and valuable in big cities. Not only that the noise map can create contour mapping, but it is also able to examine the potential impacts of future development plans and their surroundings. For this project, the mapping for KTM stations has allowed engineers and safety officers to evaluate the noise levels and plan for the future.

By doing this research, it also allows people to raise awareness on safety, health, and environmental issues of railway trains. The details of this project have allowed it to be pushed for a greater transparency and accepted by the public, thus, creating more awareness for the development of noise mapping.

\section{ACKNOWLEDGEMENT}

The authors would like to thank KTMB for their assistance. Not to forget, our sincerest gratitude to all of those who took part directly and indirectly in this research.

\section{REFERENCES}

[1] Fritschi L, Brown AL, Kim R, et al. Burden of disease from environmental noise: Quantification of healthy life years lost in Europe. World Health Organization 2011; 1-106.

[2] Passchier-Vermeer W, Passchier WF. Noise exposure and public health. 
Environmental health perspectives 2000; 108 Suppl: 123-31.

[3] Ouis D. Annoyance Caused by Exposure to Road Traffic Noise: An Update. Noise \& Health 2002; 415: 69-79.

[4] Berglund B, Lindvall T, Schwela DH. Guidelines for community noise: World Health Organisation. 5.

[5] Münzel T, Schmidt FP, Steven S, et al. Environmental Noise and the Cardiovascular System. Journal of the American College of Cardiology 2018; 71: 688-697.

[6] Vér I, Beranek L. Noise and Vibration Control Engineering. Epub ahead of print 2005. DOI: 10.1002/9780470172568.

[7] Ko JH, Chang S Il, Lee BC. Noise impact assessment by utilizing noise map and GIS: A case study in the city of Chungju, Republic of Korea. Applied Acoustics 2011; 72: 544-550.

[8] de Noronha Castro Pinto FA, Moreno Mardones MD. Noise mapping of densely populated neighborhoods - Example of Copacabana, Rio de Janeiro - Brazil. Environmental Monitoring and Assessment 2009; 155: 309-318.

[9] Yang Z, Li Z, Dollevoet RPBJ. An explicit integration finite element method for impact noise generation at squat. 1-8.

[10] Health N, Yuen FK, Programme OH, et al. Year : 2014 | Volume : 16 | Issue : 73 | Page : 427--436 A vision of the environmental and occupational noise pollution in Malaysia. 2018; 1-9.

[11] Alférez JR, Vanhooreweder B, SeguésSegues F, et al. Best practice in strategic noise mapping. 2013; 36.

[12] Department of Environment. The Planning Guidelines for Environmental Noise Limits and Control Book One. 2007; 1-34.

[13] Lumpur K, Lumpur K, Minister T, et al. KL-Ipoh train service likely to see 20,000 more passengers per month. 2009; $1-2$. 